\title{
Factores pronósticos y predictivos del carcinoma de próstata en la biopsia prostática
}

\author{
De Torres Ramírez I. \\ Servicio de Anatomía Patológica. Hospital Universitario Vall'dHebrón. Barcelona.
}

Actas Urol Esp. 2007;31(9):1025-1044

\section{RESUMEN \\ FACTORES PRONÓSTICOS Y PREDICTIVOS DEL CARCINOMA DE PRÓSTATA EN LA BIOPSIA PROSTÁTICA}

En este trabajo de revisión se exponen los criterios diagnósticos de cáncer en la biopsia prostática así como el significado de otras lesiones morfológicas (PIN de alto grado, hiperplasia adenomatosa atípica, ASAP y atrofia proliferativa inflamatoria) o variaciones histológicas en el contexto de la biopsia. Se presentan los parámetros histológicos fundamentales de utilidad pronóstica que se recomienda informar en la biopsia prostática de rutina: grado histológico de Gleason, tipo histológico del tumor, $\mathrm{n}^{\circ}$ de cilindros invadidos, cuantificación tumoral, localización de la biopsia y permeación linfovascular. Se destacan asimismo otros marcadores pronósticos y predictivos de carácter molecular, actualmente en estudio y probablemente involucrados en la progresión tumoral.

Palabras clave: Predictivo. Pronóstico. Histológico. Molecular. Próstata. Cáncer.

\section{ABSTRACT}

PROGNOSIS AND PREDICTIVE FACTORS OF PROSTATE CANCER IN THE PROSTATIC BIOPSY

This paper reviews the morphological cancer diagnosis criteria on needle biopsies, the predictive meaning of the pathological lesions of HGPIN, HAA, and P.I.A and the peculiar histopathological patterns in prostatic adenocarcinoma. We present the histological parameters that the pathologist has to informe in the diagnositic, on the routine prostate needle biopsy: Gleason histological degree, histological type, number of invaded cilindres, percentage of tumor in each cylinder, location of the biopsy and ymphovascular invasion. We also emphasize the importance of new predictive biomarkers nowadays in study and probably involved in tumor progression.

Keywords: Predictive. Prognosis. Histological. Molecular. Prostate. Cancer.

$\mathrm{E}$ l papel del patólogo en la valoración de la biopsia prostática juega un papel decisivo para establecer el diagnóstico de cáncer de próstata. El estudio histopatológico de la biopsia prostática es esencial para definir el tratamiento y el pronóstico del paciente. En la última década el screening de la población masculina a través del PSA sérico, la ecografía transrectal y la implantación de la biopsia extensiva y/o por saturación ha incrementado la posibilidad de diagnosticar pequeños focos de cáncer o un mínimo cáncer que va a implicar en la mayoría de los casos una pros- tatectomía radical. Las técnicas de inmunohistoquímica con citoqueratinas de alto peso molecular (34 beta E12) y p63 son de mucha utilidad para corroborar la ausencia de capa basal en los focos sospechosos y confirmar un mínimo foco de adenocarcinoma o apoyar en caso contrario la benignidad del proceso $^{1,2}$. Es conocido sin embargo que la negatividad de inmunotinción para células basales en glándulas sospechosas no necesariamente indican malignidad y algunos patrones de glándulas benignas pueden morfológicamente aparentar neoplasia, habiéndose descrito que glán- 
dulas benignas incluso pueden disponerse alrededor de filetes nerviosos imitando una invasión perineural $^{3}$. Se han descrito por otra parte patrones de PIN de alto grado que simulan adenocarcinoma y adenocarcinomas con epitelio estratificado que pueden simular PIN de alto grado ${ }^{4}$. Por último el reconocimiento de las lesiones acinares atípicas (ASAP) ${ }^{5}$ y de algunas lesiones inflamatorias peculiares recientemente descritas de atrofia proliferativa inflamatoria (PIA) ${ }^{6,7}$, ha supuesto para el patólogo enfrentarse a una mayor complejidad en la interpretación y diagnostico de la biopsia prostática. Es por ello fundamental conocer que parámetros morfológicos deben constar en el informe patológico de la biopsia prostática y que por su relevancia clínica van a dar una información valiosa al urólogo para el diagnóstico y pronóstico del paciente con cáncer de próstata. El presente trabajo presenta una actualización de las últimas entidades y las nuevas perspectivas en el abordaje de la biopsia prostática con especial énfasis en los factores pronósticos y predictivos.

\section{CRITERIOS MORFOLÓGICOS DEL ADENOCARCINOMA PROSTÁTICO Y DE SUS VARIANTES}

En el estudio morfológico de la biopsia prostática es recomendable seguir unas pautas y enmarcar el diagnóstico de la biopsia en una de las siguientes categorías diagnósticas: (1) adenocarcinoma, (2) proliferación acinar pequeña y atípica (ASAP), (3) neoplasia intraepitelial de alto grado (HGPIN), (4) inflamación o (5) tejido prostático benigno ${ }^{8}$.

La información histopatológica de la biopsia va a ser extremadamente útil para que el urólogo establezca una actitud terapéutica de mayor o menor agresividad según la probabilidad de invasión extracapsular o de progresión que se derive de los datos que el patólogo aporta: extensión del tumor en cada cilindro, localización del tumor y grado histológico de malignidad según la el grado de Gleason. Otros hallazgos morfológicos como la invasión perineural, densidad microvascular, permeación linfovascular, ploidía de DNA aunque pueden aumentar el valor predictivo de los anteriores, no están todavía validados como factores con valor pronóstico independiente.
El diagnóstico de adenocarcinoma en la biopsia prostática se basa en una combinación de hallazgos arquitecturales y citológicos (Fig. 1). La mayoría de adenocarcinomas se diagnostican con la tinción de hematoxilina-eosina (H\&E) y únicamente cuando existe un pequeño foco sospechoso será de utilidad practicar técnicas de inmunohistoquímica. Los criterios morfológicos que se aplican en el diagnóstico de cáncer son:

1. Arquitecturales: basados en el patrón infiltrativo de las glándulas a bajos aumentos (X100) (distorsión arquitectural, espacio interglandular irregular, tamaño variable de las glándulas, contornos glandulares irregulares) .

2. Citológicos: basados en las características nucleares a grandes aumentos (X250, X400) tamaño nuclear, hipercromasia y presencia de nucleolo (>1,50 mm), para lo cual los cortes deberán ser finos con una tinción $\mathrm{H} \& \mathrm{E}$ bien contrastada.

Algunos hallazgos morfológicos que se observan ocasionalmente aunque no concluyentes de cáncer pueden ayudar al diagnostico como son la presencia de cristales acidofilicos intraluminales (productos de degradación mineral y proteica de los acinis glandulares con alto contenido en calcio, fósforo y azufre) si bien no especifico de carcinoma ya que se observan en algunas hiperplasias, puede ser de utilidad en las biopsias de metástasis de adenocarcinoma de origen desconocido ${ }^{9}$. Otro hallazgo usual es la presencia de mucina amorfa, ácida (Azul Alcian a pH 2,5 +) y discretamente basofilica en luces glandulares a diferencia de la secreción de mucina neutra (PAS +) intraglandular en glándulas normales. La presencia de mucina ácida no es tampoco especifica de carcinoma ya que puede observarse en lesiones benignas como la hiperplasia adenomatosa atípica, la adenosis esclerosante y la neoplasia intraepitelial prostática. Otra morfología inusual y peculiar asociada a adenocarcinoma es la presencia de micronodulos colagenosos o fibroplasia mucinosa que consiste en pequeñas masas de material paucicelular eosinofilico y fibrilar de estroma que comprime los acinis neoplásicos (Fig. 1B), debidos probablemente a la extravasación de mucina ácida en el estroma prostático circundante. Este hallazgo se observa en el $0,6 \%$ de las biopsias y en el $12,7 \%$ de las prostatectomías y en general asociados a adenocarcinomas de tipo mucinoso ${ }^{10}$. 


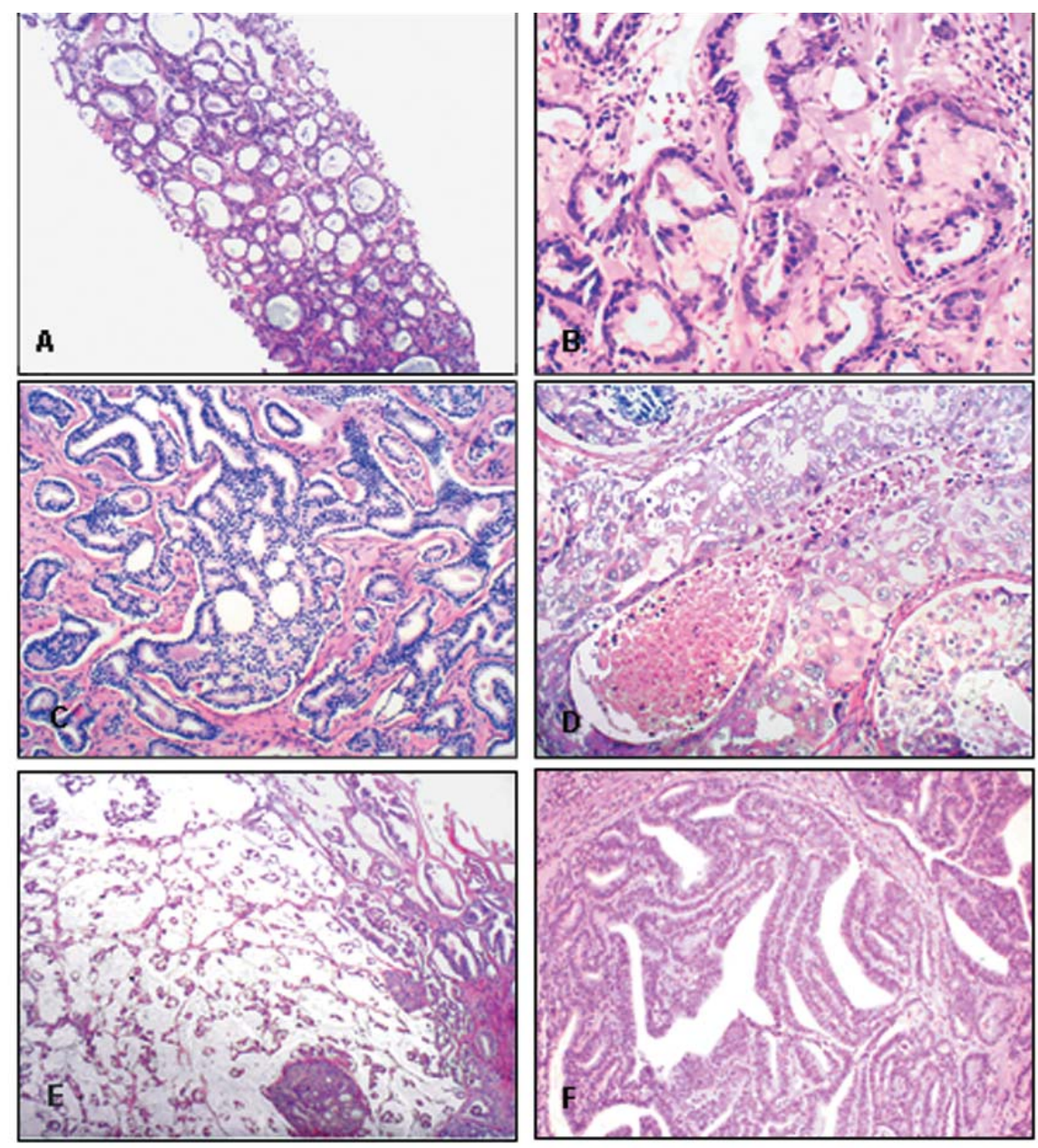

FIGURA 1. A) Adenocarcinoma acinar variante pseudohiperplásica Gleason 3+3. B) Fibroplasia mucinosa con nódulos colagenosos en adenocarcinoma acinar Gleason 3+3. C) Patrón 4 cribiforme con márgenes mal circunscritos. D) Nidos sólidos con necrosis tumoral y cariorrexis (comedonecrosis) Gleason 5+5. E) Carcinoma coloide o mucinoso Gleason 4+4. F) Adenocarcinoma ductal Gleason 4+4.

sello, carcinoma de células pequeñas, carcinoma sarcomatoide. Dado que en la biopsia solo hay una escasa representación de la totalidad de tumor y se desconoce el porcentaje del componente histológico distinto al acinar, se recomienda que en informe anatomopatológico se haga constar como:

- Adenocarcinoma de próstata con morfología ductal (Fig. 1F).

- Adenocarcinoma de próstata con diferenciación mucinosa .

- Adenocarcinoma de próstata con áreas de células en anillo de sello ya que en estos casos es frecuente que haya un componente acinar asociado.

- Carcinoma adenoescamoso.

- Carcinoma de células pequeñas.

- Carcinoma sarcomatoide.

- Carcinoma urotelial (afectando ductos y acinis prostáticos sin invasión estromal con lo cual puede ser de origen vesical, o afectando acinis y estroma o primario uretral prostático).

- Carcinoma adenoide quístico. Los tres primeros tipos histológicos, en los que puede además

La mayoría de adenocarcinomas prostáticos (mas del 90\%) que se diagnostican en la biopsia son de tipo acinar o convencional. Se han descrito recientemente variaciones morfológicas de adenocarcinoma acinar que si bien no son tipos histológicos (no tienen implicaciones clínicas ni pronósticas) sí permiten al patólogo su reconocimiento como adenocarcinoma convencional: atrófico, pseudohiperplásico (Fig. 1A), de células espumosas ('foamy cell') con células de Paneth, glomeruloide, hipernefroide... Esta morfología en el diagnóstico histopatológico ha de ser informada en términos meramente descriptivos. Existen otros tipos histológicos distintos al adenocarcinoma convencional $^{11}$ que pueden ser identificados en la biopsia: ductal, mucinoso (Fig. 1E), en anillo de haber un componente de adenocarcinoma acinar asociado, serán tipificados posteriormente en la pieza de prostatectomía, teniendo en cuenta que, si el urólogo decide otro tratamiento, ya se ha indicado la agresividad que confiere el tipo histológico tumoral en el informe de la biopsia prostática.

\section{PIN de alto grado y la hiperplasia} adenomatosa atípica en la biopsia prostática

La lesión de PIN de alto grado (HGPIN) considerada la lesión precursora de la mayoría de adenocarcinomas de grado intermedio/alto grado originados en próstata periférica, se asocia a la presencia de adenocarcinoma en zona periférica en más del $85 \%$ de los $\operatorname{casos}^{12}$. La presencia de 
PIN de alto grado en la biopsia prostática es poco frecuente oscilando alrededor del $5 \%{ }^{13}$, en tanto que el riesgo de cáncer en la $1^{\underline{a}}$ biopsia consecutiva está estimado entre el 23-35\%14,15. El hallazgo de extensas áreas de PIN de alto grado no se correlaciona con un aumento en concentraciones séricas de PSA total ni libre ${ }^{16,17}$, lo que seria explicable por la integridad de las glándulas afectadas por PIN, en contraposición con la ausencia de capa basal en las acinis neoplásicos en los que la célula secretora atípica contacta directamente con el estroma circundante. Se ha observado recientemente que el riesgo de cáncer prostático, tras un diagnóstico patológico de HGPIN en la biopsia, esta relacionado con el número de cilindros practicados en la biopsia de seguimiento ${ }^{18}$. Así el valor predictivo del PIN de alto grado ha disminuido, de una tasa de recurrencia media antes del año 2000 de $36 \%$ a una tasa del $21 \%$ en estudios posteriores ${ }^{19}$. Esto quizás es debido a varios motivos:

1. La actual práctica de biopsia extensiva protocolizada que aumenta la tasa de detección precoz de cáncer.

2. El menor porcentaje de adenocarcinoma mínimo que se asocia a HGPIN

3. Los focos de HGPIN no asociados a cáncer concomitante.

Las áreas HGPIN expresan AMACR con una intensidad similar al carcinoma, pero estudios semicuantitativos han demostrado menor intensidad significativa en aquellas áreas de PIN respecto a las áreas de carcinoma invasivo ${ }^{20,21}$.

La hiperplasia adenomatosa atipica (HAA), considerada por algunos la lesión precursora del adenocarcinoma de zona transicional, puede representar un problema diagnóstico en la biopsia prostática extensiva que incluya dicha zona. En la serie de Yang $^{22}$ (2002) con 40 casos de HAA procedentes de adenomectomías, RTUs y prostatectomías se observó positividad focal e intensa para células basales en el 100\% de los casos con inmunotinción para citoqueratina basal y únicamente positividad leve en un 10\% para AMACR . En otro estudio Jiang ${ }^{23}$ también observó en su serie de 11 casos de HAA una positividad leve para AMACR solo en 3 casos. Por lo tanto la tinción de inmunohistoquímica para p504S/AMACR ayuda en la mayoría de los casos de hiperplasia adenomatosa atípica, pero no en todos, a diferenciarla del adenocarcinoma.

\section{Proliferación acinar pequeña y atípica (ASAP) en la biopsia prostática.}

La morfología de "pequeña proliferación acinar atípica" conocida como ASAP (Atypical Small Acinar Proliferation) se observa en el 3-5\% de las biopsias $^{5}$. Esta proliferación acinar atípica no es en sí una entidad patológica, sino una categoría diagnóstica o expresado de otro modo un conjunto de hallazgos morfológicos en la biopsia que no permiten al patólogo establecer con claridad de que tipo de lesión se trata. Es preferible utilizar el termino de "pequeño foco de glándulas con atipia" a asentar un diagnóstico de malignidad o benignidad ya que: (1) el numero de glándulas del foco es muy limitado, (2) no se puede descartar se trate de un foco de adenosis o HGPIN distorsionado, (3) no podemos diferenciar glándulas atróficas de la variante de adenocarcinoma atrófico en un pequeño foco, (4) si hay inflamación asociada puede tratarse de atipia reactiva y (5) el artefacto de la biopsia puede distorsionar el tejido prostático en el foco que se esta valorando.

Los factores que determinan el diagnóstico de proliferación acinar atípica son.

- Tamaño:

- Pequeño numero de acinis ( $<5$ glándulas )en el foco.

- Tamaño pequeño del foco acinar (media de $0.4 \mathrm{~mm})$.

- Grupo acinar pequeño en el margen del cilindro.

- Rasgos histopatológicos: ausencia de una morfología clara:

- Distorsión de los acinis.

- Ausencia de criterios completos de malignidad (atipia pero no meganucleolo).

- Patrón acinar adherido.

- Pérdida del foco sospechoso tras efectuar nuevo corte para inmunohistoquímica.

- Foco con expresión negativa para CK basal pero sin criterios de malignidad.

- Criterio de posible benignidad pero con PIN asociado.

- Grupo acinar atrófico con ausencia de capa basal.

\section{- Inflamación:}

- Prominente inflamación en el grupo acinar presuntamente benigno que lo distorsiona.

- Atipia celular reactiva a la inflamación con nucléolo e hipercromasia. 
El valor predictivo de ASAP según las series oscila entre un 40\% y 50\%. El riesgo de cáncer en la segunda biopsia, con un diagnostico previo de ASAP, oscila en el 50\% representando el resto lesiones reactivas, con mayor frecuencia acinis atróficos ${ }^{24-29}$.

La incidencia de ASAP ha disminuido en los últimos años tras la introducción del marcador AMACR en el estudio rutinario de la biopsia de próstata. En un estudio reciente comparan el valor predictivo de ASAP en los años 1997-2000 respecto a los años 2000-2005, se ha observado un descenso de su valor predictivo desde $45 \%$ en el primer grupo al $37 \%$ en el segundo grupo ${ }^{19}$. Este cambio en el valor predictivo puede atribuirse a: (1) el estudio de mas cilindros en la biopsia extensiva utilizada actualmente, puesto que si se detecta un ASAP en uno de los cilindros, con frecuencia se diagnostica adenocarcinoma en algún cilindro restante, resolviendo así el problema y (2) la introducción del anticuerpo para inmunohistoquimica de la a-Methylacyl-Coa-Racemasa, muy resolutiva en un alto porcentaje de casos. Iczowsky ${ }^{30}$ en su serie de biopsias con ASAP, consiguió resolver el $80 \%$ de los casos, utilizando la citoqueratina $34 \mathrm{bE} 12$ y la P504S. En otro estudio retrospectivo de biopsias con diagnóstico de ASAP e inmunotinción con CK basal 34bE 12 aplicando sobre estos casos una inmunotinción de AMACR se logró dilucidar el $31 \%$ de sus casos ${ }^{31}$. En la serie de Molinié ${ }^{32}$ utilizando un cocktail de p63/AMACR en 104 casos de ASAP, se pudo resolver hasta el $87 \%$ de los casos, la mayoría como focos de adenocarcinoma. En una amplia revisión de 567 lesiones de ASAP procedentes de 4.046 biopsias remitidas como caso consulta a un grupo de uropatólogos expertos se observó, que tras estudio inmunohistoquímico con citoqueratinas de alto peso molecular, p63 y AMACR, la lesión que más simulaba cáncer era la atrofia parcial (35.8\%) con negatividad total para citoqueratina basal en el $13 \%$ y positividad dudosa en el $87 \%$ de estos casos. El segundo tipo de lesión no tumoral $(25,7 \%)$, corresponde a glándulas benignas aglutinadas artefactadas con inmunoexpresión positiva para AMACR en el 64\% de casos e inmunotinción negativa para citoqueratina basal en el 19\%, insuficiente por otra parte para asentar un diagnostico de adenosis ${ }^{18}$.

\section{Atrofia Proliferativa Inflamatoria (P.I.A): significado en la biopsia prostática}

El papel de la inflamación crónica en la carcinogénesis prostática esta siendo replanteada de nuevo, al demostrarse recientemente alteraciones somáticas de los genes implicados en las defensas frente al daño inflamatorio, durante el ciclo de lesión y reparación tisular ${ }^{33-34}$. Existen diversos estudios poblacionales en los que se encuentra un incremento en el riesgo relativo de contraer cáncer de próstata en pacientes con antecedentes de prostatitis o algún episodio de enfermedades de transmisión sexual. Se dispone también de datos epidemiológicos sobre genética que implican algunas variantes germinales de genes asociados con aspectos inmunológicos de la inflamación en la modulación del riesgo de cáncer prostático $^{35}$. La presencia de acinis con atrofia del epitelio en próstata periférica ha sido una morfología clásicamente reconocida por los pató$\operatorname{logos}^{36-38}$. Dado que este tipo de atrofia usualmente se asocia a inflamación crónica y aguda, y en base a los trabajos de De $\mathrm{Marzo}^{6}$ se definió la lesión de "atrofia proliferativa inflamatoria" o PIA considerándola una nueva lesión precursora en el desarrollo del cáncer prostático y/o PIN de alto grado (Fig. 2). En la morfología de PIA, las células de tapizamiento de la atrofia acinar muestran un peculiar aspecto proliferativo con aumento del tamaño nuclear y presencia de nucleolo en el contexto de una intensa inflamación periacinar y estromal (Fig. 3). Se ha propuesto, siguiendo el esquema de Rushka ${ }^{39}$, una clasificación histológica de las lesiones de PIA en los siguientes tipos: atrofia simple, hiperplasia post-atrófica y patrón mixto (atrofia simple/hiperplasia post-atrófica). En la actualidad estos patrones morfológicos están siendo objeto de estudios multicéntricos para su estandarización. En las áreas de PIA en próstata periférica las células epiteliales proliferativas muestran un aumento del tamaño nuclear y presencia de nucleolo con un grado intermedio entre células de epitelio normal y células epiteliales del HGPIN ${ }^{6,39}$. Las glándulas atróficas en la lesión de PIA tienen una apariencia hipercromática a bajos aumentos pero conservan la configuración de doble capa presente en la próstata normal (células basales y secretoras luminales). Sin embargo, el compartimento basal es más 


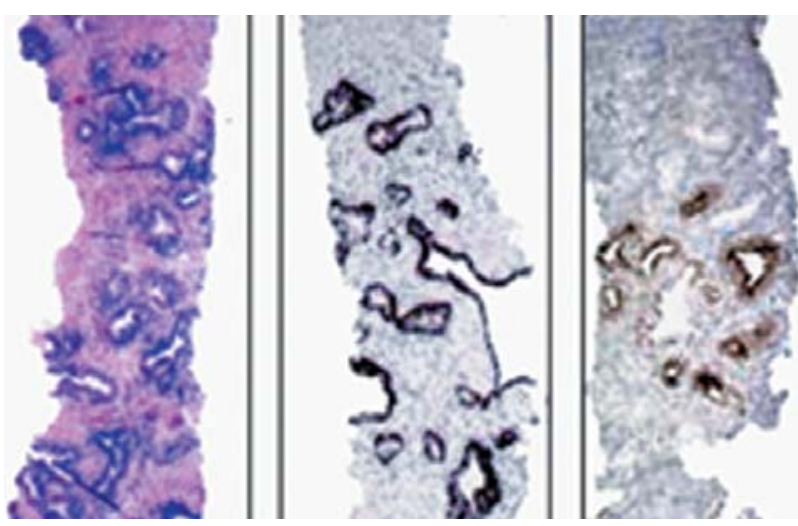

FIGURA 2.- Biopsia prostática con extensa atrofia proliferativa inflamatoria (P.I.A.) (imagen izquierda). En la figura del centro se observa preservación de capa basal con inmunorreactividad para citoqueratina $34 b E 12$. Leve inmunorreactividad para AMACR/P504S en los acinis atróficos.

claro, y la proliferación cambia desde el epitelio basal al luminal, como ocurre en el HGPIN (Fig. 3a). Estas células epiteliales de la atrofia tipo PIA representarían un tipo de célula epitelial "intermedia" con una morfología entre célula basal y célula secretora prostática con ausencia de expresión para p63 y p27 Kip1, intensa coexpresión de queratinas CK5,8,18, así como de receptor c-MET y débil expresión para PSA y receptor de andrógenos ${ }^{40}$. Este tipo de célula intermedia de la lesión de PIA esta siendo postulada como posible célula "diana" del estrés oxidativo, en la carcinogénesis prostática ${ }^{6,7,41}$.

Se ha relacionado la patogénesis molecular del cáncer prostático con alteraciones somáticas de genes implicados en las defensas frente al daño inflamatorio durante el ciclo de lesión y reparación tisular ${ }^{33,34}$. La reciente caracterización de la atrofia inflamatoria proliferativa o P.I.A. como una nueva lesión putativa precursora de cáncer, se basa en aspectos morfológicos y moleculares que atrofia proliferativa inflamatoria (PIA) comparte con la neoplasia de próstata intraepitelial prostática de alto grado (HGPIN) y el adenocarcinoma prostática $(\mathrm{CaP})$ :

- Aspectos morfológicos : (a) la localización periférica de todas estas lesiones (b) la alta incidencia de PIA en prostatectomías con HGPIN y cáncer así como la distribución multifocal en próstata periférica (c) la observación en algunos casos de una clara continuidad morfológica entre la lesión de PIA y áreas de HGPIN o su proximi-

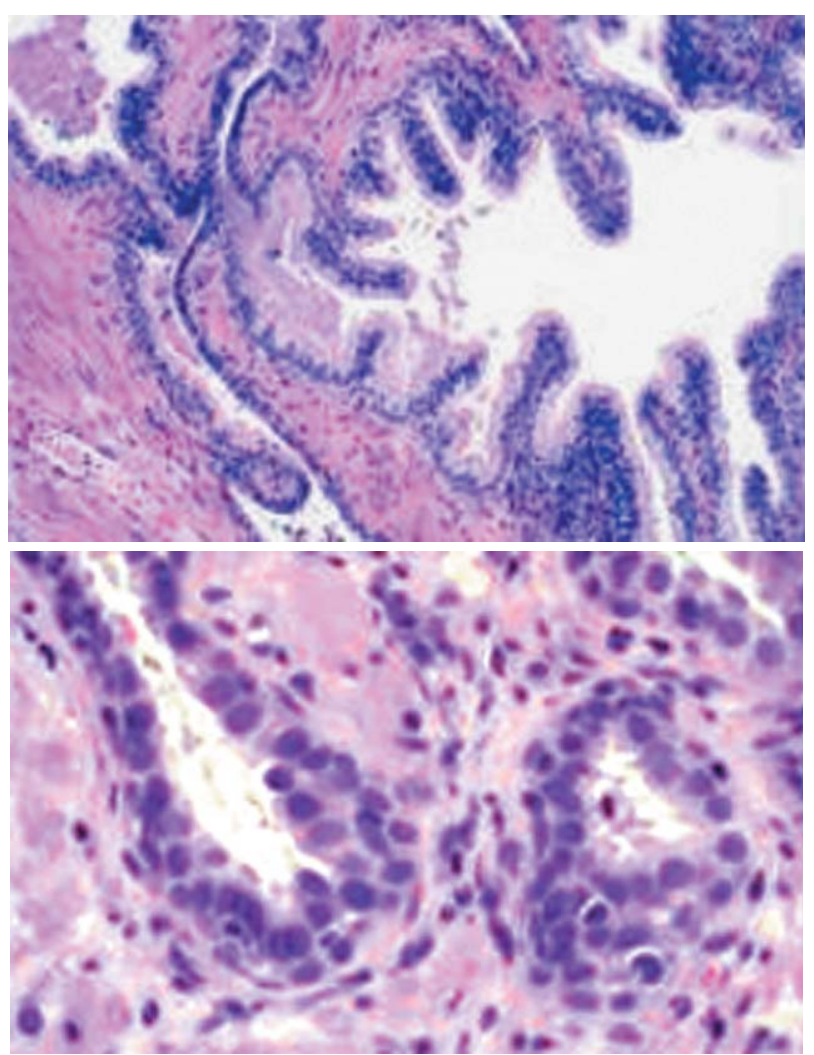

FIGURA 3. A) (imagen superior). Foco de PIN de alto grado en continuidad con área de atrofia proliferativa. B) (imagen inferior). Glándulas atróficas con epitelio proliferativo con núcleos grandes e hipercromáticos en el contexto de inflamación caracteristico de P.I.A.

dad de $<100 \mathrm{~mm}$ tanto con áreas de HGPIN como con focos de $\mathrm{CaP}^{6,7,42}$.

- Aspectos moleculares: El perfil molecular de la PIA es similar al HGPIN y al CaP. Se ha demostrado que células epiteliales de PIA presentan cambios moleculares de respuesta al estrés oxidativo con expresión de altos niveles de GSTAl y COX-2 ${ }^{42-44}$, mutaciones de $553^{45}$ e hipermetilación en el gen promotor del GSPT1 ${ }^{7}$. La pérdida de función de GSTP1 en la PIA, podría generar células de PIN y CaP, al incrementar la susceptibilidad al daño genómico secundario a los agentes oxidantes inflamatorios y a los carcinógenos de la dieta. Existen también estudios cromosómicos con FISH que demuestran similitudes moleculares entre PIA y PIN de alto grado con ganancias en el cromosoma 8 en ambas lesiones precursoras $^{46}$.

En resumen, los principales cambios moleculares descritos en las lesiones de PIA que justificarían la hipótesis de posible lesión precursora 
del adenocarcinoma prostático serían la expresión aumentada para Ki-67 (marcador de replicación celular) y Bcl-2, (pudiendo contribuir a una mayor resistencia a la apoptosis), la menor expresión de p27 (al igual que en PIN de alto grado y el CaP) la sobreexpresión para K5 y c-MET; y expresión laxa de K14, la negatividad para p63 en el compartimiento luminal epitelial de la lesión de PIA, con fenotipo de "célula intermedia" entre la células basal y secretora, las anormalidades a nivel del cromosoma 8 detectadas por FISH, el incremento en las mutaciones de p53, p16 y del receptor de andrógenos, y por último el incremento en la frecuencia de metilación de islas GpC del gen GSTP1.

En la actualidad hay gran controversia en el significado clínico de las lesiones de PIA ya que algunos autores no han observado su relación con HGPIN ${ }^{47,48}$ y no todos los PIN de alto grado o carcinomas de zona periférica se asocian a áreas de atrofia proliferativa inflamatoria ${ }^{42}$. En definitiva, los focos de PIA en próstata periférica podrian ser consecuencia de una respuesta proliferativa asociada a la edad y a estímulos microambientales que provocarian alteraciones genómicas, originando así focos de neoplasia intraepitelial de alto y finalmente adenocarcinoma.

Se requieren sin embargo muchos más estudios moleculares con series amplias en tejido prostático humano patológico para confirmar la nueva hipótesis de lesión de PIA como precursora de cáncer prostático. Es importante remarcar que en el informe anatomopatológico de momento no se recomienda la utilización de este término y si se observa debe describirse como inflamación y atrofia glandular.

\section{FACTORES PRONÓSTICOS Y PREDICTIVOS EN LA BIOPSIA PROSTÁTICA}

Los factores pronósticos son aquellos parámetros que pueden predecir la conducta biológica y la agresividad de un tumor ${ }^{49}$. Estos factores se han clasificado en dos categorias: (1) factores "pronósticos" o que predicen la recidiva o progresión de un tumor independiente del tratamiento y (2) factores "predictivos" o aquellos capaces de predecir la respuesta o resistencia después de un tratamiento específico. Actualmente no existen marcadores predictivos con evidencia aplicables a la biopsia de próstata, es decir al contrario de lo que ocurre en otros carcinomas, como el de mama en que la expresión cuantitativa de receptores hormonales en la biopsia predice la respuesta al tamoxifeno, en el cáncer de próstata no ocurre lo mismo con los receptores de andrógenos y la respuesta a hormonoterapia. Algunos parámetros pronósticos basados en la morfología son básicos y aplicables en la biopsia prostática para que el urólogo pueda delinear a través de los denominados nomogramas clínicos, las estrategias terapéuticas más adecuadas a cada paciente.

\section{Factores pronósticos morfológicos}

Los parámetros morfológicos que deben constar en el informe anatomopatológico de la biopsia prostática para el diagnóstico de rutina y que han sido validados en la literatura como factores pronósticos son el tipo histológico, el grado histológico, el número de cilindros invadidos y el porcentaje de invasión de los mismos ${ }^{50}$.

\section{Grado histológico de Gleason en la punción biopsia prostática}

$\mathrm{El}$ sistema de gradación de Gleason debe efectuarse siempre en la biopsia de próstata ya que se ha demostrado como un indicador pronóstico junto con el PSA sérico y el estadio clínico lo que va a determinar la actitud terapéutica en muchos casos.

La gradación de Gleason utilizada desde 1966 sólo se modificó ligeramente en 1974 introduciendo en el patrón 3 la arquitectura cribiforme y papilar, y en el patrón 4 la arquitectura de glándulas coalescentes. En 1977 se redefinió una arquitectura cribiforme distinta para el patrón 4 y se precisó la morfología de comedocarcinoma para el patrón 5. La uropatología en esta última década ha presentado algunas novedades que ha hecho necesario la revisión del sistema de gradación de Gleason utilizado:

1) El abordaje actual de la biopsia prostática con numerosos cilindros muy finos que mapean la próstata con carcinoma en estadio a veces muy precoz.

2) La descripción de nuevas variantes morfológicas del adenocarcinoma acinar: glomeruloide, espumoso, pseudohiperplásico, atrófico que no estaban catalogados dentro del sistema de gradación. 
3) La introducción de la inmunohistoquímica con marcadores de células basales (CKbasal 34bE12, p63). y recientemente el AMACR con lo cual pequeñas lesiones anteriormente catalogadas como de Gleason 1+1 o 1+2 hoy podemos filiar como adenosis/HAA o bien algunos patrones cribiformes de HGPIN hoy podemos constatar que se trata de adenocarcinoma con patrón 4 por la ausencia de marcadores basales y positividad para AMACR.

Al objeto de considerar los posibles cambios necesarios en el sistema de gradación de Gleason se celebró en San Antonio de Tejas, la Conferencia de Consenso de la Sociedad Internacional de Patología Urológica (ISUP) en la que intervinieron tanto patólogos como urólogos de prestigio internacional $^{3}$. La gradación de Gleason se debe efectuar inicialmente a pequeños aumentos $(4 \mathrm{X}, 10 \mathrm{X})$ en los que se determina la relación glándula-estroma para la arquitectura y posteriormente utilizar aumentos mayores (X25, X40) para los detalles citológicos y glandulares para por ejemplo distinguir entre patrones 3-4 o corroborar los focos de necrosis. Si se valora la biopsia de inicio a grandes aumentos probablemente estaremos sobregradando el tumor. Los principales cambios introducidos en la gradación se refieren a patrones en el adenocarcinoma acinar y a la gradación de otros tipos histológicos:

Patrón 1 y 2: el grado sumatorio $2(1+1), 3$ $(1+2)$ o $4(2+2)$ no debe utilizarse en biopsias prostáticas ya que la mayoría corresponden a tumores de zona transicional incidentales que se observan en material de resección transuretral prostática o adenomectomías por hiperplasia glandular benigna. En el diagnóstico de la biopsia no debe usarse ya que: (1) no se ha demostrado buena correlación con el grado posterior de la prostatectomía que suele siempre ser de mayor grado (2) induce al urólogo a error al pensar que se trata de un tumor indolente y (3) existe escasa reproducibilidad en esta gradación, incluso para uropatólogos expertos.

Patrón 2 y 3: el grado sumatorio $5(3+2) o$ $(2+3)$ es poco frecuente y probablemente el patrón 2 sea debido la coexistencia de un adenocarcinoma de zona transicional biopsiado en algún cilindro, pero también se confunde con el patrón 4 de tipo hipernefroide y hay que constatar para diagnosticar un patrón 2 en los cilindros la periferia de las glándulas bien circunscrita. El patrón 3 puede cambiar la actitud terapéutica y así un paciente con PSA sérico bajo y con este grado sumatorio de $6(3+3)$ o menor, podrá beneficiarse de un tratamiento con braquiterapia. Así el score sumatorio 7 se interpretará como moderadamente diferenciado cuando los patrones sean $3+4$ o pobremente diferenciado con los patrones $4+3$, ya que en este último caso se sabe que aumenta la probabilidad de afectación extracapsular del tumor. El cirujano puede tener en cuenta estos patrones así como el porcentaje de extensión de tumor en la biopsia para plantearse prostatectomía amplia con vandeletas neurovasculares o preservarlas para evitar la impotencia ${ }^{51}$.

Se establecen en la revisión unos criterios estrictos para definir la morfología cribiforme que usualmente es patrón 4 a menos que esté constitutuido por glándulas bien circunscritas y delimitadas sin irregularidades en el borde de su periferia y con puentes de grosor uniforme que no sean mayores que los espacios luminales. Este infrecuente patrón cribiforme 3 es el que se puede confundir con HGPIN, el diagnostico de carcinoma se establecerá por la negatividad de las glándulas a marcadores basales, el patrón de adosamiento glandular y las áreas de invasión perineural y extensión extraprostática que frecuentemente se asocian a este patrón.

En cuanto al patrón 4 que en la clasificación original constaba solo como patrón hipernefroide posteriormente ya se introdujeron las morfologias de "glándulas fusionadas" y morfología "cribiforme" siendo éstas las mas frecuentes en este patrón (Fig. 1C).

El patrón 5 que a veces plantea problemas en la valoración de comedonecrosis pues se ha observado que ocasionalmente un patrón cribiforme 4 puede tener focos de necrosis central, el grupo de consenso ha redefinido la comedonecrosis que tiene que ser estricta en el patrón 5 con presencia de cariorrexis y células necróticas en el centro de la necrosis especialmente si se observa un patrón cribiforme (Fig. 1D). 
El grado sumatorio 8-10 (adenocarcinoma escasamente diferenciado) es también crucial porque el urólogo según el porcentaje de extensión del tumor en la biopsia podría plantear al paciente otras opciones terapéuticas a la prostatectomía radical.

En las biopsias prostáticas post-hormonoterapia ni en las biopsias de las metástasis ${ }^{52}$ ya que el sistema de Gleason esta basado en la arquitectura y relación de las glándulas neoplásicasestroma la cual se altera tanto en los tratamientos hormonales como en la implantación de glándulas prostáticas neoplásicas en otros tejidos como el hueso.

¿CÓMO RECOMIENDA LA ISUP GRADAR LAS VARIACIONES MORFOLÓGICAS DE ADENOCARCINOMA ACINAR PROSTÁTICO?

- Carcinoma de células espumosas o "Foamy cell" carcinoma: $3+3$

- Adenocarcinoma con micronódulos de colágeno o Fibroplasia mucinosa: $3+3$

- Presencia de estructuras glomeruloides: es poco frecuente y no hubo consenso (el 50\% asignó un patrón 3 y el otro 50\% patrón 4)

- Adenocarcinoma pseudohiperplásico: 3+3

- Adenocarcinoma atrófico: 3+3

¿CÓMO SE DEBEN INFORMAR EN LA BIOPSIA LOS PATRONES SECUNDARIOS CON ESCASO PORCENTAJE?

- Si el patrón primario es 5 ó 4 y el secundario es de bajo grado y representa $<5 \%$ del tumor hay que ignorarlo y gradarlo como 5+5 o 4+4

- Si se trata de un tumor mínimo en la biopsia y el patrón primario es de 3 en un 5\% con algunas glándulas con patrón 4 , deberá gradarse como $4+3$ pues se presupone un error de muestreo en la toma biopsia o al menos se debe hacer constar en el informe la problemática suscitada.

- Por el contrario, en la biopsia prostática con tumor representativo y cualquier porcentaje de patrón secundario de alto grado 4 ó 5 aunque sea $<5 \%$ se ha de informar como secundario. Así si tenemos 98\% patrón 3 y $2 \%$ patrón 5 el sumatorio deberá ser 3+5.

¿ES NECESARIO INFORMAR DEL PATRÓN “TERCIARIO” EN LA BIOPSIA?

En la biopsia prostática si nos encontramos tres patrones distintos (patrón 3,4 y 5) en varias proporciones similares, se deberá informar como alto grado 8-10, si en alguna proporción aunque sea la menor observamos patrón 4 o 5 . Así si por ejemplo en la biopsia tenemos un score total de patrón primario y secundario de $3+4$ y hay además un patrón terciario de 5 , se deberá gradar como 8 $(3+5)$. En principio en la biopsia sola debe gradarse el score sumatorio de dos patrones ya que la gradación histológica de Gleason interviene en las decisiones del urólogo y es un parámetro importante en los nanogramas predictivos que utilizan a menudo para valorar la terapéutica a instaurar, evaluar el pronóstico del paciente después de la prostatectomía o el pronóstico post-radioterapia ${ }^{53-}$ 55. En las piezas de prostatectomía es opcional pudiendo informar del patrón terciario aunque no se ha demostrado su valor pronóstico.

¿Y SI LA BIOPSIA TIENE TUMOR CON DIFERENTES GRADOS EN LOS DIFERENTES CILINDROS?

El grupo de consenso en este aspecto apoya el informar los diferentes grados en los distintos cilindros si estos se remiten por separado y valorar globalmente los cilindros cuando se remiten juntos. En el trabajo de Kunz ${ }^{56}$ se demostró que cuando en un cilindro el core era de $4+4$ y en los otros de $3+4$ o $4+3$ el resultado en la pieza de prostatectomía era de $4+4$ superponible a las biopsias de otros casos con score global en los cilindros de $4+4$. Se ha observado por otra parte que el patrón de Gleason más alto detectado en el cilindro con mayor porcentaje de tumor, se correlaciona con el grado de Gleason de la pieza de prostatectomía ${ }^{57}$. Frecuentemente los cilindros que remite el urólogo suelen estar fragmentados siendo muy difícil asignar el porcentaje que tiene un patrón determinado. Por ello se ha consensuado que en estos casos prevalecerá el grado del mayor porcentaje tumoral asignándole un patrón secundario al mínimo porcentaje del tumor observado en el cilindro fragmentado. Así si el score de los cilindros óptimos es de 3+3 y hay uno subóptimo fragmentado de patrón 4 se deberá asignar un grado histológico de 3+4.

El sistema de gradación nuclear de la OMS que valora los cambios nucleares de anaplasia con tres grados 1, 2 y 3 según la atipia nuclear es un dato opcional que se puede utilizar además del grado histológico de Gleason pero en la practica no se suele informar ya que aisladamente no tiene capacidad pronostica ${ }^{58}$. 
En conclusión el grado sumatorio de Gleason sigue siendo en la actualidad uno e los parámetros pronósticos más potente en el cáncer de próstata. La reciente revisión de la Conferencia de Consenso sobre el Grado histológico de Gleason en el cáncer prostático ${ }^{3}$, ha permitido abordar muchas de las problemáticas planteadas en el sistema de gradación original, estableciendo unos criterios morfológicos muy útiles a la hora de uniformizar los diagnósticos y evitar las controversias que se habían suscitado en estos últimos años. La gradación histológica de Gleason en la biopsia prostática sigue siendo uno de los parámetros patológicos más importante ya que interviene en los nanogramas clínicos predictivos utilizadas por el urólogo junto a otros factores clínicos (PSA sérico total, \% de PSA libre, estadiaje TNM... ) para evaluar la supervivencia libre de enfermedad a los 5 años y plantear la mejor estrategia terapéutica en cada paciente ${ }^{53-55}$.

\section{Tipo histológico}

Si bien el adenocarcinoma acinar es el que con mayor frecuencia se observa en una biopsia prostática hay que tener presente que en la biopsia se pueden presentar otros tipos histológicos con peor pronóstico, como el adenocarcinoma ductal $^{59}$ (Fig. 1F) o el carcinoma coloide ${ }^{60}$ (Fig. $1 \mathrm{E})$. Se ha definido por consenso que ambos tipos histológicos deberán gradarse histológicamente como patrón sumatorio de Gleason $8(4+4)$ reflejando su peor conducta evolutiva.

El tipo histológico de carcinoma de células pequeñas o carcinoma neuroendocrino de célula pequeña, con inmunoexpresión para marcadores neuroendocrinos como la sinaptofisina o cromogranina A. no debe nunca gradarse, ya que se trata de un tipo histológico distinto al adenocarcinoma acinar poco diferenciado y por tanto con una histología, inmunoperfil y comportamiento clínico comparable a su contrapartida pulmonar tanto en su agresividad clínica como en la respuesta al tratamiento oncológico especifico ${ }^{61}$.

\section{Número de cilindros invadidos y cuanti- ficación de tumor en la biopsia prostática}

El número de cilindros remitidos en los que el patólogo observa invasión por adenocarcinoma es un dato importante en el informe patológico de la biopsia prostática ya que ha sido correlacionado con el grado histológico de Gleason, el estadio patológico, y el volumen tumoral en las consecuentes piezas de prostatectomía ${ }^{13,62,63}$. Por otra parte el número de cilindros invadidos también se ha correlacionado recientemente con un mayor riesgo de márgenes quirúrgicos positivos, recidiva bioquímica, progresión tumoral y no respuesta a la radioterapia después de la prostatectomía ${ }^{64-70}$.

La cantidad de tumor que el patólogo observa en los cilindros depende muchas veces de varios factores como son el volumen de tumor real, el número de biopsias que se obtienen, el procedimiento técnico de obtención de las biopsias con mayor o menor fragmentación de los cilindros, la distribución multifocal del cáncer y la selección previa de pacientes. No hay consenso en la literatura de como cuantificar la extensión del tumor en los cilindros. Existen dos métodos de cuantificación que se emplean:

1. Medir en mm. la longitud de tumor - ya sea en cada cilindro si se envían por separado, o la longitud tumoral total en todos los cilindros de cada lóbulo - utilizando incrementos lineales de $0,5 \mathrm{~mm}$.

2. Calcular el porcentaje de tumor en los cilindros conjuntamente -\% de tumor global respecto al total de los cilindros o por separado \% de tumor en cada cilindro- utilizando incrementos porcentuales de 5 a $10 \%$.

Si bien la presencia de alto porcentaje de tumor en múltiples cilindros y la bilateralidad se correlaciona con un mayor volumen prostático y estadio patológico avanzado en la consiguiente pieza de prostatectomía ${ }^{71}$, no ocurre así en el caso de observar escaso tumor en la biopsia. El detectar un pequeño porcentaje de tumor o adenocarcinoma mínimo en uno o más cilindros, no es garantía de tumor clínicamente insignificante en la pieza de prostatectomía radical ${ }^{72-74}$.

Según algunos autores, cuando a la presencia de un solo foco de tumor mínimo/ diminuto (definido como tumor de $<$ de $1 \mathrm{~mm}$. o invasión de $<$ $5 \%$ en un solo cilindro) se asocia un grado de Gleason menor o igual a 6 y concentraciones bajas de PSA sérico, se puede predecir la presencia de cáncer clínicamente insignificante con un $83 \%$ de confianza ${ }^{75}$. La presencia de un tumor 
diminuto o mínimo en la biopsia de próstata oscila mucho según las series desde un $3 \%^{75}, 7.3 \%{ }^{76}$ al $10.9 \%{ }^{77}$. En definitiva el hallar un foco mínimo de cáncer en una biopsia no es por sí solo predictivo de tumor clínicamente insignificante, ya que sólo un 44\%-53\% de estos casos presentan un volumen menor o igual a $0,1 \mathrm{ml}^{73,75}$. López JI et $a .^{78}$ han observado que combinando grado histológico de Gleason con la extensión en milímetros de invasión en la biopsia se puede predecir la extensión extracapsular, así en su serie de 290 prostatectomías radicales, el 100\% de los casos que observaron un score de Gleason $>7$ y extensión de $>12 \mathrm{~mm}$ de tumor en la punción biopsia se observó enfermedad extracapsular en la prostatectomía. Asimismo la presencia de tumor bilateral es indicativa de multifocalidad y sugiere volumen tumoral significativo, dato esencial en pacientes que no van a ser sometidos a prostatectomía y que por tanto no van a tener un estadiaje patológico.

En la información sobre la extensión y cantidad tumoral que el patólogo debe transmitir al urólogo en la biopsia prostática debe constar:

- El no de cilindros invadidos.

- La cantidad de tumor en los cilindros (es opcional el método puede ser en mm. o valorar el porcentaje).

- La bilateralidad.

Algunos estudios prometedores utilizan múltiples parámetros morfológicos y bioquímicos (porcentaje de tumor en la biopsia, PSA, grado histológico en la biopsia) junto a técnicas de imagen y redes neurales artificiales, con resultados prometedores lo que podría ser en el futuro una metodología útil para valorar la conducta biológica en cáncer prostático ${ }^{79-82}$.

\section{Localización del tumor en la biopsia prostática}

La localización del cilindro prostático puede tener implicaciones pronósticas en el caso de invasión tumoral del cilindro procedente de vesícula seminal o del tejido adiposo extraprostático. En ambos casos se aporta valiosa información del probable estadio patológico tumoral ya se ha demostrado una correlación significativa entre la invasión de estas estructuras y afectación extraprostática (pT3) en la pieza de prostatectomía ${ }^{29}$.
Por el contrario el hallazgo de células ganglionares o filetes musculares invadidos por tumor no presupone enfermedad extraprostática ya que si bien el tejido adiposo intraprostático es excepcional, es frecuente encontrar células ganglionares o filetes fibromusculares en el estroma prostático.

Por otra parte la localización de la biopsia puede también orientar al patólogo sobre la benignidad de estructuras "simuladoras" de adenocarcinoma como es la presencia de glándulas de Cowper en la biopsia del ápex, o el epitelio atrófico de zona central en biopsia de la base. El lugar de procedencia de los cilindros en la biopsia prostática es además útil al establecer el diagnóstico de proliferación acinar atípica no diagnostica de cáncer ya que en este caso se conoce la zona en donde deberá repetirse la biopsia para obtener un resultado concluyente. La localización del tumor en la biopsia puede tener interés en el estudio de la pieza de prostatectomía si es parcial y no se observa tumor residual, pues permitirá al patólogo seriar y dirigir el estudio con múltiples bloques en la zona anatómica para detectar el cáncer mínimo.

La localización del tumor puede intervenir en la estrategia terapéutica y así una invasión de tejido adiposo extraprostático o la invasión extensa de los cilindros de base puede indicar un tumor locamente avanzado, también la afectación de cuello vesical o posible margen positivo, obliga al urólogo a plantear una actitud quirúrgica más agresiva en la prostatectomía radical o bien optar por un tratamiento alternativo radioterápico.

\section{Invasión perineural}

La invasión perineural que se identifica en un 20\%-38\% de las biopsias prostáticas ${ }^{83,84}$ no es un factor pronóstico independiente, pero en el caso de extensa invasión perineural en la biopsia prostática, aumenta el riesgo de infiltración extraprostática en el estadiaje patológico ${ }^{85-87}$ y podría ser un factor predictivo de metástasis ganglionares y progresión tumoral tras la prostatectomía. En algunos estudios este parámetro se ha demostrado como factor pronostico independiente junto al grado histológico de Gleason y así una importante invasión perineural en la biopsia asociada a un grado de Gleason $>7$, muestra una significativa menor respuesta a la radioterapia ${ }^{88-90}$. 


\section{Invasión linfovascular}

La permeación vascular o linfática por nidos tumorales es muy infrecuente observarla en la biopsia. Hay que diferenciar una permeación vascular /linfática con el artefacto estromal y acinar post-fijación que se observa ocasionalmente y siempre es recomendable efectuar una técnica de inmunohistoquímica para identificar endotelios como el CD34 o CD31. La permeación vascular se observa aproximadamente en el 38\% de las piezas de prostatectomía sin embargo en análisis multivariante no ha demostrado ser un factor pronóstico independiente ${ }^{91,92}$. La permeación vascular que muy ocasionalmente se puede identificar en biopsia prostática probablemente es un dato pronóstico de importancia como se ha demostrado en la prostatectomía en la que recientemente se ha demostrado una correlación con volumen tumoral, presencia de metástasis ganglionares, recidiva bioquímica y progresión de enfermedad $^{93}$.

\section{Marcadores moleculares pronósticos en la biopsia prostática}

La dificultad del adenocarcinoma prostático en obtener marcadores pronósticos radica en su marcada heterogeneidad de tal forma que dentro del grupo de los tumores órgano confinados va a existir un subgrupo con una conducta biológica más agresiva. La investigación sobre marcadores moleculares en cáncer prostático esta dirigida a identificar marcadores específicos que puedan distinguir aquellos cánceres agresivos de los no agresivos $^{94}$. En la actualidad se están analizando múltiples marcadores moleculares de las denominadas "vías de señalización celular" (ciclo celular, angiogénesis, apoptosis, invasividad...), moléculas intensamente imbricadas entre sí, algunas de los cuales, conociendo los mecanismos de interacción en el desarrollo del adenocarcinoma, podrían aumentar el poder predictivo de los parámetros morfológicos ya mencionados posibilitando así dianas terapéuticas especificas.

Uno de los avances introducidos en la metodología para el estudio de la expresión de estos marcadores en el tejido tumoral ha sido el "tissue microarray o microarray de tejido" (TMA). Esta nueva tecnología está permitiendo el análisis de la expresión de un gen, simultáneamente en varios tejidos procedentes de muchos tumores distintos $^{95}$ pudiendo efectuarse el análisis de expresión mediante técnicas de inmunohistoquímica, hibridización in situ, FISH y CISH, con un menor coste y una mayor rapidez ${ }^{96}$. El análisis de marcadores moleculares pronósticos en tejido tumoral prostático clásicamente ha sido efectuados sobre líneas celulares y en material procedente de prostatectomías, evaluando principalmente la expresión de proteínas mediante técnicas de inmunohistoquímica. La mayoría de los marcadores moleculares que se correlacionan con progresión tumoral y seguimiento clínico no han sido todavía validados para el uso clínico. Estos marcadores podrían en un futuro aplicarse en las biopsias prostáticas pre-tratamiento de forma rutinaria, posibilitando la implementación de dianas terapéuticas individualizadas según el perfil o "firma genética" de cada paciente. A continuación se describen los posibles marcadores moleculares predictivos más interesantes hasta el momento descritos en tejido prostático humano.

\section{Ploidia DNA}

Algunos estudios han sugerido que el análisis de ploidía de DNA podría aportar información clínica predictiva en algunos pacientes La mayoría de tumores de bajo grado son diploides y la mayoría de alto grado de Gleason son aneuploides correlacionándose el estudio de la ploidía con estadiaje y grado de malignidad ${ }^{97,98}$. No existen todavía métodos estandarizados de aplicabilidad clínica ya que la citometría de flujo óptima se realiza sobre tejido tumoral en fresco, no siendo posible obtenerlo de las biopsias prostáticas o prostatectomías en las que el tumor usualmente no se identifica fácilmente en el estudio macroscópico.

\section{Índice de proliferación celular (Ki67)}

Ki-67 está presente en las células en división pero no en células estacionarias o en reposo siendo un marcador potencial de proliferación celular. Mediante inmunohistoquímica, utilizando el anticuerpo MIB-1 en material parafinado procedente de prostatectomías, se ha demostrado que el índice proliferativo, asociado al grado histológico de Gleason aumenta su valor predictivo pro- 
nóstico ${ }^{86}$. Estudios previos habían observado una correlación entre el índice proliferativo tumoral y el tiempo de supervivencia libre de enfermedad después de la prostatectomía ${ }^{99,100}$. En pacientes con enfermedad avanzada, la expresión nuclear de Ki67 parece ser un parámetro eficaz para establecer un subgrupo de mal pronósti$\mathrm{co}^{101}$. Existen algunos estudios realizados en cilindros procedentes de biopsia prostática y prostatectomía consecutiva, en los que el índice proliferativo con Ki67 se demuestra como parámetro pronóstico independiente predictivo de supervivencia $^{102}$. Se ha observado la existencia de un patrón proliferativo creciente en glándulas prostáticas desde tejido normal, PIN de alto grado, a cáncer prostático ${ }^{103,104}$. Algunos autores han demostrado por el contrario que la expresión de Ki67 observada en las biopsias preoperatorias tiene menor capacidad predictiva para la progresión bioquímica post-prostatectomía que los parámetros clásicos pronósticos como PSA, grado sumatorio de Gleason y estadiaje $\mathrm{pT}^{105}$.

\section{p53}

El significado de la mutación de p53 en cáncer prostático sigue siendo controvertido. La proteína p53 es el producto de expresión del gen supresor p53 implicado en el ciclo celular y en la vía de la apoptosis celular. Su inhibición permite que haya tiempo para la reparación del DNA antes de la división celular. Mutaciones en este gen posibilitan que la célula pueda dividirse antes de reparar su DNA ,conllevando alto riesgo inestabilidad genética y transformación maligna. Las inmunoexpresión de p53 en cáncer de próstata es indicador de peor pronóstico incluso con grado histológico bajo o moderado. Estudios recientes demuestran que la expresión nuclear de p53 es un marcador predictor de recidiva después de cirugia, incluso en aquellos pacientes con hormonoterapia neoadyuvante, con un riesgo de recidiva del $90 \%$ a los 36 meses $^{106,107}$. Si bien hay consenso sobre la utilidad clínica de la inmunoexpresión de p53 en las piezas de prostatectomía radical, no se ha demostrado su aplicabilidad en la biopsia prostática. Así algunos estudios realizados en biopsia prostática y en su correspondiente prostatectomía radical, observan escasa correlación entre la expresión de p53 en el tumor de las biopsias respecto a la del tumor en la prostatectomía ni con la recidiva clínica ${ }^{108,109}$. Estos resultados podrían explicarse por las características de heterogeneidad y multifocalidad propias del adenocarcinoma de próstata. Otros autores sin embargo postulan que la expresión de p53 es un importante biomarcador en la biopsia prostática y así Brewster ${ }^{110}$ en su estudio de 76 pacientes en los que evalúa la expresión para p53, ECadherina, Bcl-2 y CD44 en cilindros prostáticos, demuestra mediante análisis multivariante que los únicos marcadores pronósticos independientes de recidiva después de la prostatectomía son el grado histológico de Gleason y la expresión de p53. En varios estudios con biopsias prostáticas pre-tratamiento de pacientes con radioterapia posterior debido a enfermedad localmente avanzada, se demuestra la inmunoexpresión de p53 como factor predictivo independiente de recidiva $^{111,112}$. Por todo ello y aunque p53 podría ser un marcador biológico útil, dada la polémica existente en los trabajos son necesarios más estudios multicéntricos para confirmar su utilidad clínica.

\section{Bcl-2}

El proto-oncogen Bcl-2 esta involucrado en la regulación de la muerte programada o apoptosis. Este gen codifica una proteína cuya función es inhibir la apoptosis. En tejido prostático tumoral se observa sobreexpresado en el $27 \%-68 \%$ y se ha correlacionado con tasa de recidiva bioquímica tras la prostatectomía 113,114 .

\section{P27}

E1 gen p27 que pertenece a la familia de las kinasas ciclina-dependientes (Cip/Kip), codifica una proteína inhibidora del ciclo celular, regulando negativamente la proliferación celular. La expresión de p27 está consistentemente elevada en próstata normal. Estudios en piezas de prostatectomía y en microarrays de tejido han demostrado que la menor expresión de p27 en cáncer de próstata clínicamente localizado, es un parámetro independiente predictivo de recidiva bioquímica después de la prostatectomía ${ }^{115-117}$. No hay todavía estudios en biopsias prostáticas pretratamiento que confirmen el potencial predictivo de este marcador. 


\section{Cox-2}

La expresión de Cox-2 en tejidos prostáticos y concretamente en cáncer de próstata ha sido objeto de numerosos estudios ${ }^{118-120}$. Se ha demostrado con técnicas de inmunohistoquímica en diferentes tipos de cáncer, el papel de COX-2 en la angiogénesis tumoral, observando colocalización de COX-2 y algunos potentes factores angiogénicos VEGF, bFGF, PDGF y TGF-b ${ }^{121}$ (Fosslien,2001). Asimismo se le ha atribuido un papel mediador en la resistencia a la apoptosis a través de BCL-2 y TGF-beta ${ }^{122}$. En próstata se ha observado intensa inmunoexpresión para COX-2 en la lesión de P.I.A. respecto a acinis normales y una expresión heterogéneamente positiva en las áreas de PIN de alto grado y cáncer ${ }^{123}$. Recientemente se ha demostrado que el grado de Gleason, PSA sérico preoperatorio, invasión extraprostática, estado del margen, invasión de vesícula seminal y una alta expresión de COX-2 en análisis univariante, son factores predictivos significativos de recidiva bioquímica. En análisis multivariante solo el PSA preoperatorio y la expresión de COX-2 parecen ser indicadores pronósticos independientes de progresión tumoral $^{124}$. Al igual que los anteriores marcadores todavía no se ha demostrado la utilidad del Cox2 en core biopsias.

\section{VEGF, bFGF y densidad microvascular (MVD)}

El oxigeno tisular microambiental tisular y la difusión de nutrientes son insuficientes para el crecimiento del tumor por encima de $2-3 \mathrm{~mm}^{3}$ siendo imprescindible la formación de nuevos vasos o angiogénesis. En esta vía angiogénica se ponen en marcha varios mecanismos entre los que destacan la producción de sustancias angiogénicas, la activación del endotelio, la degradación de paredes capilares y la migración de células endoteliales. Aquellos tumores que conllevan mayor angiogénesis son más agresivos y de peor pronóstico. Los factores angiogénicos mas estudiados en cáncer de próstata son el factor de crecimiento fibroblástico básico (bFGF) y el factor de crecimiento vascular endotelial (VEGF). Se ha demostrado una sobreexpresión significativa de ambos factores en el PIN de alto grado y cáncer prostático respecto al tejido normal y una inten- sa correlación con la densidad microvascular 104,125,126. Por otra parte se ha observado que estos factores se asocian con la presencia de células neuroendocrinas en el tumor y en pacientes con ablación androgénica se ha demostrado una pérdida de expresión de VEGF en todas las células tumorales excepto en el subgrupo de células endocrinas, indicando que el VEGF estaría probablemente involucrado tanto en la progresión como en la regresión del cáncer prostático $^{126}$. A tenor de estos estudios se postula la expresión de los factores angiogénicos como posible biomarcador pronóstico y se esta considerando el potencial terapéutico de los inhibidores de angiogénesis en el cáncer de próstata ${ }^{127}$.

\section{Moléculas de adhesión: E-Caderina}

La E-Caderina es una importante molécula de adhesión cuya disminución en la expresión ha sido correlacionado con el grado histológico, estadio tumoral, presencia de metástasis y supervivencia $^{128,129}$. De Marzo et al. ${ }^{130}$ han demostrado con análisis multivariante que la E-Caderina, PSA sérico y grado sumatorio de Gleason se correlacionan independientemente con el estadiaje avanzado. Asimismo se ha asociado la expresión de E-Caderina con recidiva bioquímica tumoral $^{131}$ postulando que esta molécula podría ser un buen biomarcador pronostico en la biopsia prostática. Otros marcadores de adhesión han identificado un perfil génico diferencial entre cáncer de próstata invasivo y el cáncer de próstata órgano confinado correlacionándolo con su conducta clínico-biológica ${ }^{132}$.

\section{Receptores de andrógenos}

Los receptores de andrógenos (RA) son factores de trascripción nuclear que se unen a los esteroides y modulan los efectos biológicos de los andrógenos activando los genes de trascripción andrógeno-dependientes. Estos receptores parecen ser cruciales para la supervivencia y progresión en el cáncer de próstata. La mayoría de estudios intentan explicar como el cáncer de próstata hormono-dependiente se vuelve hormono-independiente en su crecimiento. Se ha observado que el cáncer prostático expresa RA incluso cuando se vuelve hormonorefractario a la deprivación androgénica ${ }^{133,134}$. El mecanismo de acti- 
vación de la función del receptor andrógenos es complicado ya que puede deberse a amplificación del gen receptor de andrógenos con consiguiente sobreexpresión del receptor que daría lugar a que un cáncer hormono-independiente presentara un aumento de sensibilidad a pequeñas cantidades de andrógenos circulantes. Por otra parte mutaciones en el gen receptor de andrógenos podrían dar lugar a cambios de la especificidad del ligando con la consecuente activación por antiandrógenos. Por ultimo el cáncer andrógeno-independiente podría progresar en ausencia de mutaciones del receptor de andrógenos por la activación de ligandos receptores andrógeno-independientes de las vías de señalización. La gran heterogeneidad de RA observada en los pacientes hormonorefractarios con escasa supervivencia puede reflejar una mayor inestabilidad genética en estos tumores que han progresado y podría ser utilizada como predictor de respuesta al tratamiento hormonal y como signo de progresión tumoral ${ }^{135}$. Estudios recientes con microarrays de tejido en muestras de prostatectomía radical de pacientes, sin hormonoterapia previa, han demostrado que niveles altos de expresión de RA se correlacionan significativamente con una menor supervivencia libre de recidiva bioquímica y con parámetros clínico patológicos de mayor agresividad tumoral ${ }^{136}$.

\section{Marcadores de la vía de señalización PI3k/AKT mTOR}

Hay estudios recientes que estudian la expresión de la vía AKT involucrada en proliferación, diferenciación y progresión del tumor ${ }^{137}$. La sobreexpresión de algunos marcadores como el PTEN se ha relacionado con estadios patológicos avanzados y se ha observado recientemente una sobreexpresión más intensa de 4EBP1 en cáncer y PIN de alto grado comparada con otros biomarcadores de la vía mTOR, postulándose como posible molécula diana, aunque se requieren múltiples estudios con correlación clínica para su validación ${ }^{138}$. Por otra parte pAKT ha demostrado una expresión significativa aumentada no solo en el tumor sino en las glándulas benignas adyacentes al tumor en comparación con tejido prostático benigno de casos control sin tumor asociado, lo que genera buenas perspectivas en su utilización en cilindros para detección de lesiones premalignas y malignas ${ }^{139}$.

\section{CONCLUSIÓN}

En el adenocarcinoma de próstata el patólogo juega un papel esencial tanto en el diagnóstico preoperatorio con la biopsia extensiva, como en la evaluación de la pieza de prostatectomía Es en la biopsia prostática donde el patólogo valida los parámetros pronósticos morfológicos y en un futuro no lejano, la expresión de marcadores moleculares en tejido que permitirán delinear al urólogo la conducta terapéutica más apropiada. Las nuevas tecnologías de microarrays de c-DNA y microarray de tejido van a permitir establecer perfiles génicos que puedan diferenciar entre aquellos adenocarcinomas de próstata clínicamente silentes que serán órganoconfinados durante muchos años, de aquellos otros que van a progresar rápidamente hacia enfermedad avanzada. En la actualidad, a pesar de que los resultados de los estudios sobre las diferentes vías y cascadas de señalización oncogénica son prometedores, no existen todavía biomarcadores moleculares predictivos aplicables en la biopsia prostática rutinaria. En los próximos años la investigación traslacional podrá acelerar el intercambio entre la investigación básica, desde los diferentes laboratorios, hacia la investigación clínica aplicada, cuyos resultados se podrán traducir en nuevas y efectivas terapias moleculares del cáncer de próstata.

Hasta entonces la correcta interpretación morfológica de las biopsias prostáticas, utilizando los parámetros consensuados, aporta en la actualidad una valiosa información para: (1) determinar estrategias en el tratamiento (quirúrgico, con radioterapia, hormonoterapia adyuvante o crioterapia) y (2) plantear ensayos clínicos multicéntricos imprescindibles para el avance en el conocimiento del cáncer prostático.

\section{REFERENCIAS}

1. Wojno KJ, Epstein JI. The utility of basal cell-specific anticytokeratin antibody (34bE12) in the diagnosis of prostate cancer. A review of 228 cases. Am J Surg Pathol. 1995; 19(3):251-260.

2. Signoretti S, Waltregny D, Dilks J. p63 is a prostate basal cell marker and is required for prostate development. Am J Surg Pathol. 2000;157:1769-1775.

3. Epstein JI, Allsbrook WC, Amin MB and the ISUP Grading Committee. The 2005 International Society of Urological Pathology (ISUP) Consensus Conference on Gleason Grading of Prostatic Carcinoma. Am J Surg Pathol. 2005;29 (9):1128-1242. 
4. Hameed O, Sublett J, Humphrey PA. Immunohistochemical stains for p63 and alpha-methylacyl Coa Racemasa versus a cocktail comprising both, in the diagnosis of prostatic carcinoma: a comparison of the immunohistochemical staining of 430 foci in radical prostatectomy and needle biopsy tissues. Am J Surg Pathol. 2005;29(5):579-587.

5. Epstein JI. Interpretation of prostate biopsies. 3er Ed. Philadelphia, PA. Lippincott Williams and Wilkins, 2002.

6. De Marzo AM, Marchi VL, Epstein JI. Nelson WG. Proliferative inflammatory atrophy of the prostate: implications for prostate carcinogenesis. Am J Pathol. 1999;155(6): 1985-1992.

7. Nakayama M, Benett CJ, Hicks JL, Epstein JI, Platz EA, Nelson WG et al. Hypermethylacion on the glutatione Stransferase-pi gene (GSTP1) CpG island is present in a subset of proliferative inflammatory atrophy lesions but not in normal or hyperplastic epithelium of the prostate: a detail study using laser-capture microdissection. Am J Pathol. 2003; 163(3):923-933.

8. Montironi R, Mazzucchelli R, Scattoni V, Bostwick DG. Pathological findings in TRUS prostatic biopsy: diagnostic prognostic and therapeutic importance. Eur Urol. Suppl. 2002;1:60-75.

9. Molberg KH, Mikhail A, Vuitch F. Crystalloids in metastatic prostatic adenocarcinoma. Am J Clin Pathol. 1994;101 (3):266-268.

10. Bostwick DG, Wollan P, Adlakha K. Collagenous micronodules in prostate cancer: a specific but infrequent diagnostic finding. Arch Pathol Lab Med. 1995; 119(2):444-447.

11. Eble JN, Sauter G, Epstein JI. (Eds). World Health Organization Classification of Tumors. Tumors of the urinary system and male genital organs. Pathology and Genetics. IARC Press, Lyon 2004 pp.160-161.

12. Bostwick DG, Grignon DJ, Hammond ME, Amin MB, Cohen M, Crawford D et al. Prognostic Factors in Prostate Cancer. College of American Pathologists Consensus Statement. Arch Path Lab Med. 2000;124(7):995-1000.

13. Wills ML, Sauvageot J, Partin AW, Gurganus R, Epstein JI. Ability of sextant biopsies to predict radical prostatectomy stage. Urology. 1998;51(5):759-764.

14. Davidson D, Bostwick DG, Qian J, Wollan PC, Oesterling JE, Rudders RA. Prostatic intraepithelial neoplasia is a risk factor for adenocarcinoma: predictive accuracy in needle biopsies. J Urol. 1995;154(4):1295-1299.

15. O’ Dowd GJ, Miller MC, Orozco R, Veltri RW. Analysis of repeated biopsy results within 1 year after a noncancer diagnosis. Urology 2000;55(4):553-559.

16. Alexander EE, Qian J, Wollan PC, Myers RP, Bostwick DG. Prostatic intraepithelial neoplasia does not appear to raise serum prostate-specific antigen concentration. Urology 1996; 47(5):693-698.

17. Morote J, Raventos CX, Encabo G, Lopez M, de Torres IM. Effect of high-grade prostatic intraepithelial neoplasia on total and percent free serum prostatic-specific antigen. Eur Urol. 2000;37(4):456-459.

18. Herawi M, Cavallo C, Kahane H. Risk of prostate cancer on rebiopsy following a diagnosis of high grade prostatic intraepithelial neoplasia (HGPIN) is related to the number of cores sampled. Mod Pathol. 2005; 18:145.

19. Schlesinger C, Bostwick DG, Iczkowsky KA. High grade prostatic intraepithelial neoplasia and atypical small acinar proliferation. Predictive value for cancer in current practice. Am J Surg Pathol. 2005;29(9):1201-1207.
20. Luo J, Zha S, Gage WR. Alpha-methylacyl CoA Racemase: a new molecular marker for prostate cancer. Cancer Res. 2002;62(8):2220-2226.

21. Rubin MA, Zhon M, Dhanasekaran SM. Alpha-Methylacyl Coenzyme A Racemase as a tissue biomarker for prostate cancer. JAMA 2002;287(13):1662-1670.

22. Yang XJ, Wu CL, Woda BA. Expression of alpha-methylacyl- CoA Racemase (P504S) in atypical adenomatous hyperplasia of the prostate. Am J Surg Pathol. 2002;26(7): 921-925.

23. Jiang Z, Woda B, Rock KL. P504S: A new marker for the detection of prostate carcinoma. Am J Surg Pathol. 2001; 25(11):1397-1404.

24. Iczkowski KA, Bassler TJ, Schwob VS, Bassler IC, Kunnel BS, Orozco RE. Diagnosis of 'suspicious for malignancy' in prostate biopsies: predictive value for cancer. Urology. 1998;51(5):749-757.

25. Renshaw AA, Santis WF, Richie JP. Clinicopathological characteristics of prostatic adenocarcinoma in men with atypical prostate needle biopsies. J Urol. 1998;159(6): 20182021.

26. Chan TY, Epstein JI. Follow-up of atypical prostate needle biopsies suspicious fro cancer. Urology. 1999;53(2):351355.

27. Borboroglu PG, Sur RL, Roberts JL, Amling CL. Repeat biopsy strategy in patients with atypical small acinar proliferation or high grade prostatic intraepithelial neoplasia on initial prostate needle biopsy. J Urol. 2001;166(3):866870 .

28. Kronz JD, Shaik AA, Epstein JI. High- grade prostatic intraepithelial neoplasia with adjacent small atypical glands on prostate biopsy. Hum Pathol. 2001;32(4):389395.

29. Epstein JI. Diagnosis and reporting of limited adenocarcinoma of the prostate on needle.biopsy. Mod Pathol. 2004; 17(3):307-315.

30. Iczkowski KA, Jiang $Z$, Tretiakova M et al. Prostatic needle biopsies with suspicious (ASAP) diagnosis: $80 \%$ resolving using P504S/AMACR and keratin 34bE12 immunostaining. Mod Pathol. 2003;16:154.

31. Jiang Z, Iczkowski KA, Woda BA, Tretiakova M, Yang XJ. P504S immunostaining boost diagnostic resolution of 'suspicious' foci in prostate needle biopsy specimens. Am J Clin Pathol. 2004;121(1):99-107.

32. Molinie V, Fromont G, Sibony M. Diagnostic utility of a p63/alpha-methylacyl.CoA racemase (P504S) cocktail in atypical foci in the prostate. Modern Pathol. 2004;17(10): 1180-1190.

33. Palapattu GS, Sutcliffe S, Bastian PJ, Platz EA, De Marzo AM, Isaacs WB. Prostate carcinogenesis and inflammation: emerging insights. Carcinogenesis. 2005;26(7):1170-1181.

34. Platz EA, De Marzo AM. Epidemiology of inflammation and prostate cancer. J Urol. 2004;171(2 Pt 2):36-40.

35. Xu J, Stolk JA, Zhang X. Identification of differentially expressed genes in human prostate cancer using subtraction and microarrays. Cancer Res. 2000;60(6):1677-1682.

36. Rich AR. On the frequency of occurrence of occult carcinoma of the prostate. Int $\mathrm{J}$ Epidemiol. 2007;36(2):274277.

37. Franks LM. Atrophy and hyperplasia in the prostate proper. J Pathol Bacteriol. 1954;68(2):617-621.

38. McNeal JE. Normal histology of the prostate. Am J Surg Pathol. 1988;12(8):619-633. 
39. Ruska KM, Sauvageot J, Epstein JI. Histology and cellular kinetics of prostatic atrophy. Am J Surg Pathol. 1998;22 (9): 1073-1077.

40. Van Leenders GJ, Gage WR, Hicks JL, van Balken B, Aalders TW, Schalken JA. Intermediate cells in human prostate epithelium are enriched in proliferative inflammatory atrophy. Am J Pathol. 2003;162(5):1529-1537.

41. Van Leenders G, Dijkman H., Hulsbergen-van de Kaa C, Ruiter D, Schalken J. Demonstration of intermediate cells during human prostate epithelial differentiation in situ and in vivo using triple staining confocal scanning microscopy. Lab Invest. 2000;80(8):1251-1258.

42. Puttzi MJ, De Marzo AM. Morphologic transition between proliferative inflammatory atrophy and high grade prostatic intraepithelial neoplasia. Urology 2000;56(5):828-832.

43. Parsons JK, Nelson CP, Gage WR, Nelson WG, Kensler TW, De Marzo AM. GSTA1 expression in normal, preneoplastic and neoplastic human prostate tissue. Prostate. 2001;49 (1):30-37.

44. Zha S, Gage WR., Sauvageot J, Saria EA, Putzi MJ, Ewing $\mathrm{CM}$ et al. Cyclo-oxigenase 2 is up-regulated in proliferative inflammatory atrophy of the prostate, but not in prostate carcinoma. Cancer Res. 2001;61(24):8617-8623.

45. Tsujimoto Y, Takayama H, Nonomura N, Okuyama A, Aozasa K. Postatrophic hyperplasia of the prostate in Japan: histologic and immunohistochemistry features and p53 mutations analysis. Prostate 2002;52(4):279-287.

46. Macoska JA, Trybus TM, Wojno KJ. 8p22 loss concurrent with 8c gain associated with poor outcome in prostate cancer. Urology 2000;55(5):776-782.

47. Anton RC, Kattan MW, Chakraborty S, Wheeler T. Postatrophic hyperplasia of the prostate. Lack of association with prostate cancer. Am J Surg Pathol. 1999;23(8): 932-936.

48. Billis A, Magna LA. Inflammatory atrophy of the prostate. Prevalence and significance. Arch Pathol Lab Med. 2003; $127(7): 840-844$.

49. Hayes DF, Bast RC, Desch CE, Fritsche H Jr, Kemeny NE, Jessup JM et al. Tumor marker grading system: a framework to evaluate clinical utility of tumor markers. J Natl Cancer Inst. 1996;88(20):1456-1466.

50. Montironi R, Navarrete R, Lopez-Beltran A. Histopathology reporting of prostate needle biopsies. 2005 update. Virchows Arch. 2006;449(1):1-13.

51. Gonzalgo ML, Bastian PJ, Mangold LA, Trock BJ, Epstein JI, Walsh PC et al. Relationship between primary Gleason pattern on needle biopsy and clinicopathologic outcomes among men with Gleason score 7 adenocarcinoma of the prostate. Urology 2006;67(1):115-119.

52. Algaba F, Epstein JI, Aldape HC. Assessment of prostate carcinoma cancer in core needle biopsy definition of minimal criteria for the diagnosis of cancer in biopsy material. Cancer. 1996;78(2):376-381.

53. Partin AW, Kattan MW, Subong EN, Walsh PC, Wojno KJ, Oesterling JE et al.: Combination of prostate-specific antigen, clinical stage and Gleason to predict pathological stage of localized prostate cancer. A multi-institutional update. JAMA 1997;227(18):1445-1451.

54. Badalament RA, Miller MC, Peller PA, Young DC, Bahn DK, Kochie $\mathrm{P}$ et al. An algorithm for predicting nonorgan confined prostate cancer using the results obtained from sextant core biopsies with prostate specific antigen level. J Urol. 1996;156(4):1375-1380.
55. Kattan MW, Wheller TM, Scardino PT. Postoperative nomogram for disease recurrence after radical prostatectomy for prostate cancer. J Clin Oncol. 1999;17(5):1499-1507.

56. Kunz GM Jr, Epstein JI. Should each core with prostate cancer be assigned a separate Gleason score? Hum Pathol. 2003;34(9):911-914.

57. Poulos CK, Daggy JK, Cheng L. Preoperative prediction of Gleason grade in radical prostatectomy specimens: the influence of different Gleason grades from multiple positive biopsy sites. Mod Pathol. 2005;18(2):228-234.

58. Montironi R, Mazzucchelli R, Scarpelli M, Lopez-Beltran A, Fellegara G, Algaba F. Gleason grading of prostate cancer in needle biopsies or radical prostatectomy specimens: contemporary approach, current clinical significance and sources of pathology discrepancies. BJU Int. 2005;95(8): 1146-1152.

59. Brinker DA, Potter SR, Epstein JI. Ductal adenocarcinoma of the prostate diagnosed on needle biopsy: correlation with clinical and radical prostatectomy findings and progression. Am J Surg Pathol. 1999;23(12):1471-1479.

60. Ro JY, Grignon DJ, Ayala AG. Mucinous adenocarcinoma of the prostate: histochemical and immunohistocehmical studies. Hum Pathol. 1990;21(6):593-600.

61. Amin M, Boccon-Gibod L, Egevad L, Epstein JI, Humphrey PA, Mikuz G et al. Prognostic and predictive factors and reporting of prostate carcinoma in prostate needle biopsy specimens. Scand J Urol Nephrol Suppl. 2005;(216):20-33.

62. Tigrani VS, Bhargava V, Shinohara K, Presti JC Jr. Number of positive systematic sextant biopsies predicts surgical margin status at radical prostratectomy. Urology 1999; 54(4):689-693.

63. Conrad S, Graefen M, Pichlmeier U, Henke RP, Hammerer PG, Huland H. Systematic sextant biopsies improve preoperative prediction of pelvic lymph node metastases in patients with clinically localized prostatic carcinoma. J Urol. 1998;159(6):2023-2029.

64. Sebo TJ, Bock BJ, Cheville JC, Lohse C, Wollan P, Zincke H. The percent of cores positives of cancer in prostate needle biopsy specimens is strongly predictive of tumor stage and volume at radical prostatectomy. J Urol. 2000;163(1):174-178.

65. Freedland SJ, Csathy GS, Dorey F, Aronson WJ. Percent prostate needle biopsy tissue with cancer is more predictive of biochemical failure or adverse pathology after radical prostatectomy than prostate specific antigen or Gleason score. J Urol. 2002;167(2 Pt 1):516-520.

66. Freedland SJ, Aronson WJ, Terris MK, Kane CJ, Amling $\mathrm{CL}$, Dorey $\mathrm{F}$ et al. The percentage of prostate needle biopsy cores with carcinoma from the more involved of the biopsy as a predictor of prostate specific antigen recurrence after radical prostatectomy: results from the Shared Equal Access Regional Cancer Hospital (SEARCH) database. Cancer. 2003;98(11):2344-2350.

67. Freedland SJ, Aronson WJ, Terris MK, Kane CJ, Amling CL, Dorsey F. The SEARCH Database Study Group. Percent of prostate needle biopsy cores with cancer is significant independent predictor of prostate specific antigen recurrence following radical prostatectomy: results from SEARCH database. J Urol. 2003;169(6):2136-2141.

68. Gancarczyk KJ, Wu H, McLeod DG, Kane C, Kusuda L, Lance $\mathrm{R}$ et al. Using the percentage of biopsy cores positive for cancer, pretreatment PSA, and highest biopsy Gleason sum to predict pathologic stage after radical prostatectomy: the Center for Prostate Disease Research nomograms. Urology 2003;61(3):589-595. 
69. Koh H, Kattan MW, Scardino PT, Suyama K, Maru N, Slawin $\mathrm{K}$ et al. A nomogram to predict seminal vesicle invasion by the extent and location of cancer in systematic biopsy results. J Urol. 2003;170(4 Pt 1):1203-1208.

70. Antunes AA, Srougi M, Dall'Oglio MF, Crippa A, Campagnari JC, Leite KR. The percentage of positive biopsy cores as a predictor of disease recurrence in patients with prostate cancer treated with radical prostatectomy BJU Int. 2005;96(9):1258-1263.

71. Lotan Y, Shariat SF, Khoddami SM, Saboorian H, Koeneman KS, Cadeddu JA et al. The percent of biopsy cores positive for cancer is a predictor of advanced pathological stage and poor clinical outcomes in patients treated with radical prostatectomy. J Urol. 2004;171(6 Pt 1): 2209-2214.

72. Bruce RG, Rankin WR, Cibull ML. Single focus of adenocarcinoma in the prostate biopsy specimen is not predictive of the pathological stage of disease. Urology 1996;48(1):75-79.

73. Hoedemaeker RF, van der Kwast TH, Schroeder FH. The clinical significance of a small focus of well-differentiated carcinoma at prostate biopsy. Br J Int. 2003;92(Suppl 2):92-96.

74. Haese A, Chaudhari M, Miller MC, Epstein JI, Huland H, Palisaar $\mathrm{J}$ et al. Quantitative biopsy pathology for the prediction of pathologically organ confined prostate cancer: A multiinstitutional validation study. Cancer. 2003;97(4): 969-978.

75. Allan RW, Sanderson H, Epstein JI. Correlation of minute (0.5 mm. or less) focus of prostate adenocarcinoma on needle biopsy with radical prostatectomy specimen: role of prostate specific antigen. J Urol. 2003;170(2 Pt 1):370372.

76. Leroy X, Aubert S, Villers A. Minimal focus of adenocarcinoma on prostate biopsy: clinicopathological correlations. J Clin Pathol. 2003;56(3):230-232.

77. Rubin MA, Dunn R, Kambham N. Should a Gleason score be assigned to a minute focus of carcinoma on prostate biopsy? Am J Surg Pathol. 2000;24(3):1634-1640.

78. Lopez JI, Etxezarraga C. The combination of milimetres of cancer sand Gleason index in core biopsy is a predictor of extraprostatic disease. Histopathology. 2006;48(6):663667.

79. Singh H, Caznto EI, Shariat SF. Six additional systematic lateral cores enhance sextant biopsy prediction of pathological features at radical prostatectomy. J Urol. 2004;171 (1):204-209

80. Augustin H, Mammerer PG, Graefen M. Insignificant prostate cancer in radical prostatectomy specimen: time trends and preoperative prediction. Eur Urol. 2003;43(1): 455460.

81. Ponchietti R, Di Loro F, Fanfani A. Estimation of prostate volume by endorectal coil magnetic resonance imaging vs. pathological volume. Eur Urol. 1999;35(1):32-35.

82. Zlotta AR, Remzi M, Snow PB. An artificial neural network for prostate cancer staging when serum prostate specific antigen is $10 \mathrm{ng} / \mathrm{ml}$. or less . J Urol. 2003;169(5):17241728.

83. Bastacky SI, Walsh PC, Epstein JI. Relationship between perineural tumor invasion on needle biopsy and radical prostatectomy capsular invasion in clinical stage B adenocarcinoma of the prostate. Am J Surg Pathol. 1993;17(4): 336-341.
84. Egan AJ, Bostwick DG. Prediction of extraprostatic extension of prostate cancer based on needle biopsy findings: perineural invasion lacks significance on multivariate analysis. Am J Surg Pathol. 1997;21(12):1496-1500.

85. Vargas SO, Jiroutek M, Welch WR. Perineural invasion in prostate needle biopsy specimens: correlation with extraprostatic extension at resection. Am $\mathrm{J}$ Clin Pathol. 1999; $111(2): 223-228$.

86. Sebo TJ, Cheville JC, Riehle DL. Perineural invasion and MIB-1 positive addition to Gleason score are significant predictors of progression after radical retropubic prostatectomy. Am J Surg Pathol. 2002;26(4):431-439.

87. Quinn DI, Henshall SM, Brenner PC, Kooner R, Golovsky D, O`Neill GF et al. Prognostic significance of preoperative factors in localized prostate carcinoma treated with radical prostatectomy: importance of percentage of biopsies that contain tumor and the presence of biopsy perineural invasion. Cancer 2003;97(8):1884-1893.

88. Bonin SR, Hanlon AL, Lee WR. Evidence of increased failure in the treatment of prostate carcinoma patients who have perineural invasion treated with three-dimensional conformal radiation therapy. Cancer 1997;79(1):75-80.

89. Anderson PR, Hanlon AL, Patchefsky A, Al-Saleem T, Hanks GE. Perineural invasion and Gleason 7-10 tumors predict increased failure in prostate cancer patients with pretreatment $\mathrm{PSA}<10 \mathrm{ng} / \mathrm{mL}$ treated with conformal external beam radiation therapy. Int $J$ Radiat Oncol Biol Phys. 1998;41(5): 1087-1092.

90. Beard CJ, Chen MH, Cote K, Loffredo M, Renshaw AA, Hurwitz $\mathrm{M}$ et al. Perineural invasion is associated with increased relapse after external beam radiotherapy for men with low-risk prostate cancer and may be a marker for occult, high-grade cancer. Int J Radiat Oncol Biol Phys. 2004;58(1): 19-24.

91. Van den Ouden D, Kranse R, Hop WC, van der Kwast TH, Schroder FH. Microvascular invasion in prostate cancer: prognostic significance in patients treated by radical prostatectomy for clinically localized carcinoma. Urol Int. 1998;60(1):17-24.

92. Epstein JI. Pathological assessment of the surgical specimen. Urol Clin North Am. 2001;28(3):567-594.

93. Shariat SF, Khoddami SM, Saboorian H, Koeneman KS, Sagalowsky AI, Cadeddu JA et al. Lymphovascular invasion is a pathological feature of biologically aggressive disease in patients treated with radical prostatectomy. J Urol. 2004;171(3):1122-1127.

94. Rubin MA. Using molecular markers to predict outcome. J. Urol. 2004;172(5 Pt 2):S18-21.

95. Kononen J, Bubendorf L, Kallioniemi A, Barlund M, Schraml P, Leighton S et al. Tissue microarrays for highthroughput molecular profiling of tumor specimens. Nat Med. 1998;4(7):844-847.

96. Merseburger AS, Anastasiadis AG, Hennenlotter J, Schilling D, Simon P, Machtens SA et al. Tissue microarrays: applications in urological cancer research. World $\mathrm{J}$ Urol. 2006;24(5):579-584. Epub 2006 Aug 9

97. Grignon DL, Hammond EH. CAP Conference XXXVI on clinical relevance of prognostic markers in solid tumors. Arch Pathol Lab Med. 1995;119(12):1122-1126.

98. Persons DL, Takai K, Gibney DJ, Katzmann JA, Lieber MM, Jenkins RB. Comparison of fluorescence in situ hybridization with flow cytometry and static image in ploidy analysis of paraffin-embedded prostate adenocarcinoma. Hum Pathol. 1994;25(7):678-683. 
99. Bettencourt MC, Bauer JJ, Sesterhenn IA, Mostofi FK, McLeod DG, Moul JW. Ki-67 expression is a prognostic marker of prostate cancer recurrence after radical prostatectomy. J Urol. 1996;156(3):1064-1068.

100. Scalzo DA, Kallakury BV, Gaddipati RV, Sheehan CE Keys HM, Savage D et al. Cell proliferation rate by MIB-1 immunohistochemistry predicts postradiation recurrence in prostatic adenocarcinomas. Am J Clin Pathol. 1998; 109(2):163-168.

101. Matsuura H, Hayashi N, Kawanmura J, Shiraishi T, Yatani R. Prognostic significance of Ki-67 expression in advanced prostate cancers in relation to disease progression after androgen ablation. Eur Urol. 2000;37(2):212217.

102. Bubendorf L, Tapia C, Gasser TC, Casella R, Grunder B, Moch $\mathrm{H}$ et al. Ki67 labeling index in core needle biopsies independently predicts tumor-specific survival in prostate cancer. Hum Pathol. 1998;29(9):949-954.

103. Mucci NR, Rubin MA., Strawderman MS, Montie JE, Smith DC, Pienta KJ. Expression of nuclear antigen Ki67 in prostate cancer needle biopsy and radical prostatectomy specimens. J Natl Cancer Inst. 2006;92(23): 1941-1942.

104. Pallares J, Rojo F, Iriarte J, Morote J, Armadans LI, de Torres I. Study of microvessel density and the expression of the angiogenic factors VEGF, bFGF and the receptors Flt-1 and FLK-1 in benign, premalignant and malignant prostate tissues. Histol Histopathol. 2006;21(8):857-865

105. Ojea Calvo A, Mosteiro Cervino MJ, Dominguez Freire F, Alonso Rodrigo A, Rodriguez Iglesias B, Benavente Delgado $\mathrm{J}$ et al. The usefulness of Ki67 expression in the biopsy specimens, to predict the biochemical progression of the prostate cancer after radical prostatectomy. Acta Urol Esp. 2004;28(9):650-660.

106. Quinn DI, Henshall SM, Head DR. Prognostic significance of p53 nuclear accumulation in localized prostate cancer treated with radical prostatectomy. Cancer Res. 2000;60 (6): 1585-1594.

107. Leibovich BC, Cheng L, Weaver AL. Outcome prediction with p53 immunostaining after radical prostatectomy in patients with locally advanced prostate cancer. J Urol. 2000;163(6): 1756-1760.

108. Stackhouse GB, Sesterhenn IA, Bauer JJ, Mostofi FK, Connelly RR, Srivastava SK et al. P53 and BCL-2 immunohistochemistry in pretreatment prostate needle biopsies to predict recurrence of prostate cancer after radical prostatectomy. J Urol. 1999;162(6):2040-2045.

109. Ruitjer E, Van de Kaa A, Alders T. Heterogeneous expression of E-Cadherin and p53 in prostate cancer and clinical implications. BIOMED-II Markers for Prostate Cancer Study Group. Mod Pathol. 1998;11(3):276-281.

110. Brewster SF, Oxley JD, Trivella M. Preoperative p53, bcl2, CD44 and E-Cadherin immunohistochemistry as predictors of biochemical relapse after radical prostatectomy. J Urol. 1999;161(4):1238-1243.

111. Huang A, Gandour-Edwards R, Rosenthal SA. P53 and bcl-2 immunohistochemical alterations in prostate cancer treated with radiation therapy. Urology 1998;51(2): 346-351.

112. Scherr DS, Vaughan ED, Wei J. Combined analysis with bcl-2 and p52 immunostaining in clinically localized prostate cancer predicts response to external beam radiotherapy. J Urol. 1999;162(1):12-16.
113. Bauer JJ, Steerhenn JA, Mostofi FK. Elevated levels of apoptosis regulator proteins p52 and bcl.2 are independent prognostic biomarkers in surgically treated clinically localized prostate cancer. J Urol. 1996;156(4):1511-1516.

114. Revelos K, Petraki C, Gregorakis A, Scorilas A, Papanastasiou $\mathrm{P}$, Koutsilieris $\mathrm{M}$. Immunohistochemical expression of $\mathrm{Bcl} 2$ is an independent predictor of time-tobiochemical failure in patients with clinically localized prostate cancer following radical prostatectomy. Anticancer Res. 2005;25(4):3123-3133.

115. Ribal MJ, Fernandez PL, Lopez-Guillermo A, Farre X, Santos Y, Gibanel R et al. Low p27 expression predicts biochemical relapse after radical prostatectomy in patients with clinically localised prostate cancer. Anticancer Res. 2003;23(6D):5101-5106.

116. Freedland SJ, de Gregorio F, Sacoolidge JC, Elshimali YI, Csathy GS, Elashoff DA et al. Predicting biochemical recurrence after radical prostatectomy for patients with organ-confined disease using p27 expression. Urology 2003;61(6): 1187-1192.

117. Li R, Wheeler TM, Dai H, Sayeeduddin M, Scardino PT, Frolov A et al. Biological correlates of p27 compartmental expression in prostate cancer. J Urol. 2006;175(2):528532

118. Kirschenbaum A, Klausner AP, Lee R, Unger P, Yao S, Liu $\mathrm{XH}$ et al. Expression of cyclooxigenase- 1 and cyclooxigenase- 2 in the human prostate. Urology 2000;56(4):671676.

119. Madaan S, Abel PD, Chaudhary KS, Hewitt R, Stott MA, Stamp GW et al. Cytoplasmic induction and over-expression of cyclooxigenase-2 in human prostate cancer: implications for prevention and treatment. $\mathrm{Br} \mathrm{J}$ Urol. 2000;86(6):736-741.

120. Tanji N, Kikugaea M, Yokohama M. Immunohistochemical study of cyclooxigenase in prostatic adenocarcinoma: relationship to apoptosis and bcl-.2 expression. Anticancer Res. 2000;20(4):2313-2319.

121. Fosslien E. Molecular pathology of cyclo-oxigenase-2 in cancer-induced angiogenesis. Ann Clin Lab Sci. 2001;31 (4):325-348.

122. Lu X, Xie W, Reed D, Bradshaw WS, Simmons DL. Nonsteroidal anti-inflammatory drugs cause apoptosis and induce cyclooxigenases in chicken embryo fibroblast. Proc Natl Acad Sci. 1995;92(17):7961-7965.

123. Zha S, Yegnasubramanian V, Nelson WG, Isaacs WB, de Marzo AM. Cyclooxigenases in cancer: progress and perspective, Cancer Letters 2004;215(1):1-20.

124. Cohen BL, Gomez P, Omori Y, Duncan RC et al. Cyclooxygenase-2 (COX-2) expression is an independent predictor of prostate cancer recurrence. Int $\mathrm{J}$ Cancer. 2006; 119(5): 1082-1087.

125. Mazzucchelli R, Montironi R, Santinelli A. Vascular endothelial growth factor expression and capillary architecture in high grade PIN and prostate cancer in untreated and androgen-ablated patients. Prostate 2000; 45(1):72-79

126. Sugamoto T, Tanji N, Sato K. The expression of basic fibroblast growth factor and vascular endothelial growth factor in prostate adenocarcinoma: correlation with neovascularization. Anticancer Res. 2001;21(1A): 77-88.

127. Ali IU, Senger DR, Smith LE. Angiogenesis as a potential biomarker in prostate cancer chemoprevention trials. Urology 2001;57(4 Suppl 1):143-147. 
128. Umbas R, Isaacs WB, Bringuier PP, Schaafsma HE, Karthaus HF, Oosterhof GO et al. Decreased E-cadherin expression is associated with poor prognosis in patients with prostate cancer. Cancer Res. 1994,54(14):39293933.

129. Aaltomaa S, Lipponen P, Ala-Opas M, Eskelinen M, Kosma VM. Alpha-cadherin expression has prognostic value in local and locally advanced prostate cancer. $\mathrm{Br} \mathrm{J}$ Cancer 1999;80(3-4):477-482.

130. De Marzo AM, Knudsen B, Chan-Tack K, Epstein JI. Ecadherin expression as a marker of tumour aggressiveness in routinely processed radical prostatectomy specimens. Urology 1999;53(4):707-713.

131. Rhodes DR, Sanda MG, Otte AP, Chinnaiyan AM, Rubin MA. Multiplex biomarker approach for determining risk of prostate-specific antigen-defined recurrence of prostate cancer. J Natl Cancer Inst. 2003;95(9):661-668.

132. Lapointe J, Li C, Higgins JP, van de Rijn M; Bair E, Montgomery K, Ferrari M et al. Gene expression profiling identifies clinically relevant subtypes of prostate cancer Proc Natl Acad Sci. U S A 2004;Jan 20;101(3):811-816. Epub 2004 Jan 7.

133. Feldman BJ, Feldman D. The development of androgenindependent prostate cancer. Nat Rev Cancer 2001;1(1): 34-35.

134. Zegarra-Moro OL, Schmidt LJ, Huang H, Tindall DJ. Disruption of androgen receptor function inhibits proliferation and androgen-refractory prostate cancer cells. Cancer Res. 2002;62(4):1008-1013.
135. Magi-Galluzzi C, Xu X, Hlatky L, Hahnfeldt P, Kaplan I, Hsiao $\mathrm{P}$ et al. Heterogeneity of androgen receptor content in advanced prostate cancer. Mod Pathol. 1997;10(8): 839-845.

136. Li R, Wheeler T, Dai H, Frolov A, Thompson T, Ayala G. High level of androgen receptor is associated with aggressive clinicopathologic features and decreased biochemical recurrence-free survival in prostate: cancer patients treated with radical prostatectomy. Am J Surg Pathol. 2004; 28(7):928-934.

137. Gao N, Zhang Z, Jiang BH, Shi X. Role of PI3K/AKT/ mTOR signaling in the cell cycle progression of human prostate cancer. Biochem Biophys Res Commun. 2003; 310(4):1124-1132.

138. Kremer CL, Klein RR, Mendelson J, Browne W, Samadzedeh LK, Vanpatten $\mathrm{K}$ et al. Expression of mTOR signaling pathway markers in prostate cancer progression. Prostate. 2006;66(11):1203-1212.

139. Merseburger AS, Hennenlotter J, Simon P, Muller CC, Kuhs U, Knuchel-Clarke R et al. Activation of the PKB/ Akt pathway in histological benign prostatic tissue adjacent to the primary malignant lesions. Oncol Rep. 2006; 16(1):79-83.

Correspondencia autora: Dra. I. de Torres

Servicio de Anatomía Patológica. Hospital Universitario Vall' dHebrón Paseig Vall`dHebrón 119-129 - 08035 Barcelona Tel.: 932746810

E-mail autora: itorres@vhebron.net

Información artículo: Original - Próstata 